
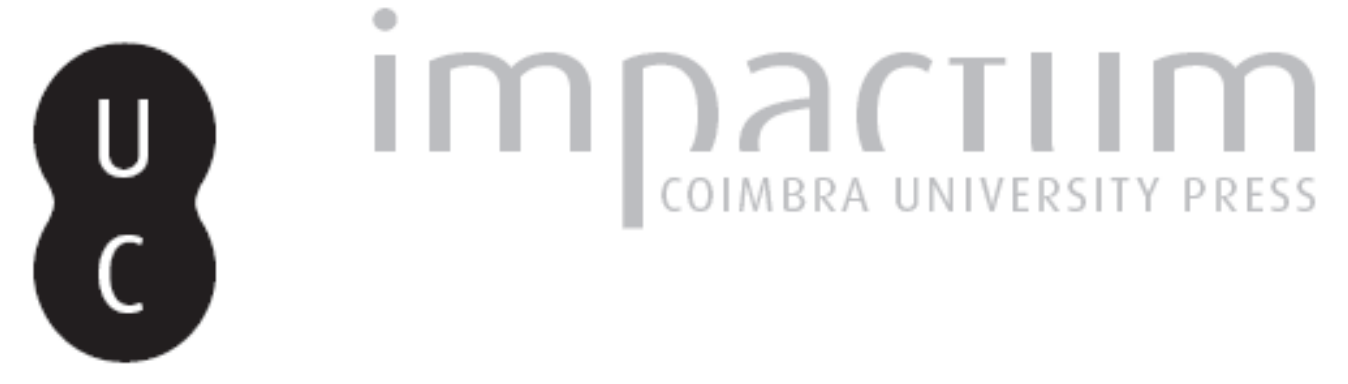

\title{
A Antiguidade no cinema: The Odyssey de Andrei Konchalovsky (1997)
}

Autor(es): $\quad$ Rodrigues, Nuno Simões

Publicado por: Associação Portuguesa de Estudos Clássicos; Instituto de Estudos Clássicos

URL $\quad$ URI:http://hdl.handle.net/10316.2/30358

DOI: $\quad$ DOI:http://dx.doi.org/10.14195/0872-2110_55_11

Accessed : $\quad$ 26-Apr-2023 14:05:36

A navegação consulta e descarregamento dos títulos inseridos nas Bibliotecas Digitais UC Digitalis, UC Pombalina e UC Impactum, pressupõem a aceitação plena e sem reservas dos Termos e Condições de Uso destas Bibliotecas Digitais, disponíveis em https://digitalis.uc.pt/pt-pt/termos.

Conforme exposto nos referidos Termos e Condições de Uso, o descarregamento de títulos de acesso restrito requer uma licença válida de autorização devendo o utilizador aceder ao(s) documento(s) a partir de um endereço de IP da instituição detentora da supramencionada licença.

Ao utilizador é apenas permitido o descarregamento para uso pessoal, pelo que o emprego do(s) título(s) descarregado(s) para outro fim, designadamente comercial, carece de autorização do respetivo autor ou editor da obra.

Na medida em que todas as obras da UC Digitalis se encontram protegidas pelo Código do Direito de Autor e Direitos Conexos e demais legislação aplicável, toda a cópia, parcial ou total, deste documento, nos casos em que é legalmente admitida, deverá conter ou fazer-se acompanhar por este aviso.

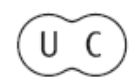




\section{Boletim de \\ Estudos Clássicos}

Associação Portuguesa de Estudos Clássicos

Instituto de Estudos Clássicos

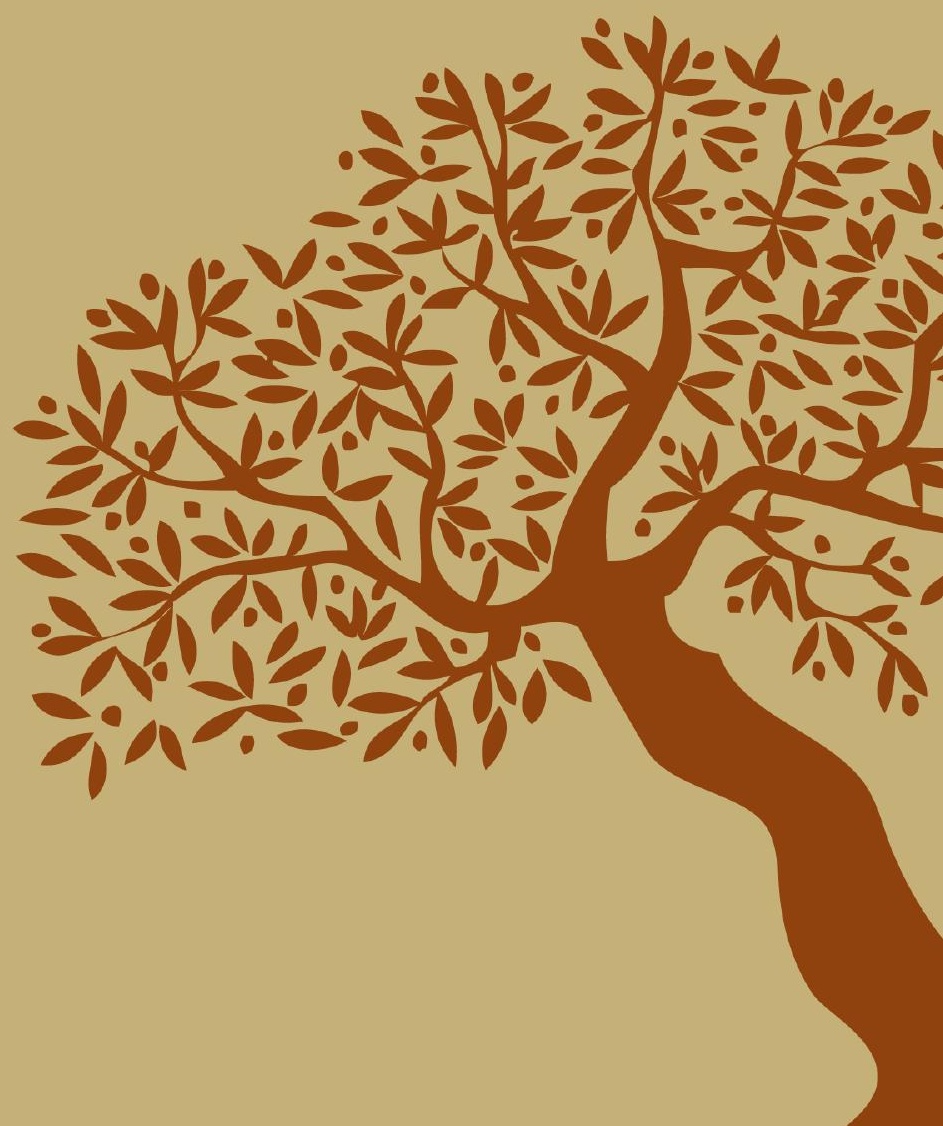

Coimbra

Junho de 2011 


\section{A ANTiguidade no Cinema: \\ THE ODYSSEY \\ DE ANDREI KONCHALOVSKY (1997)}

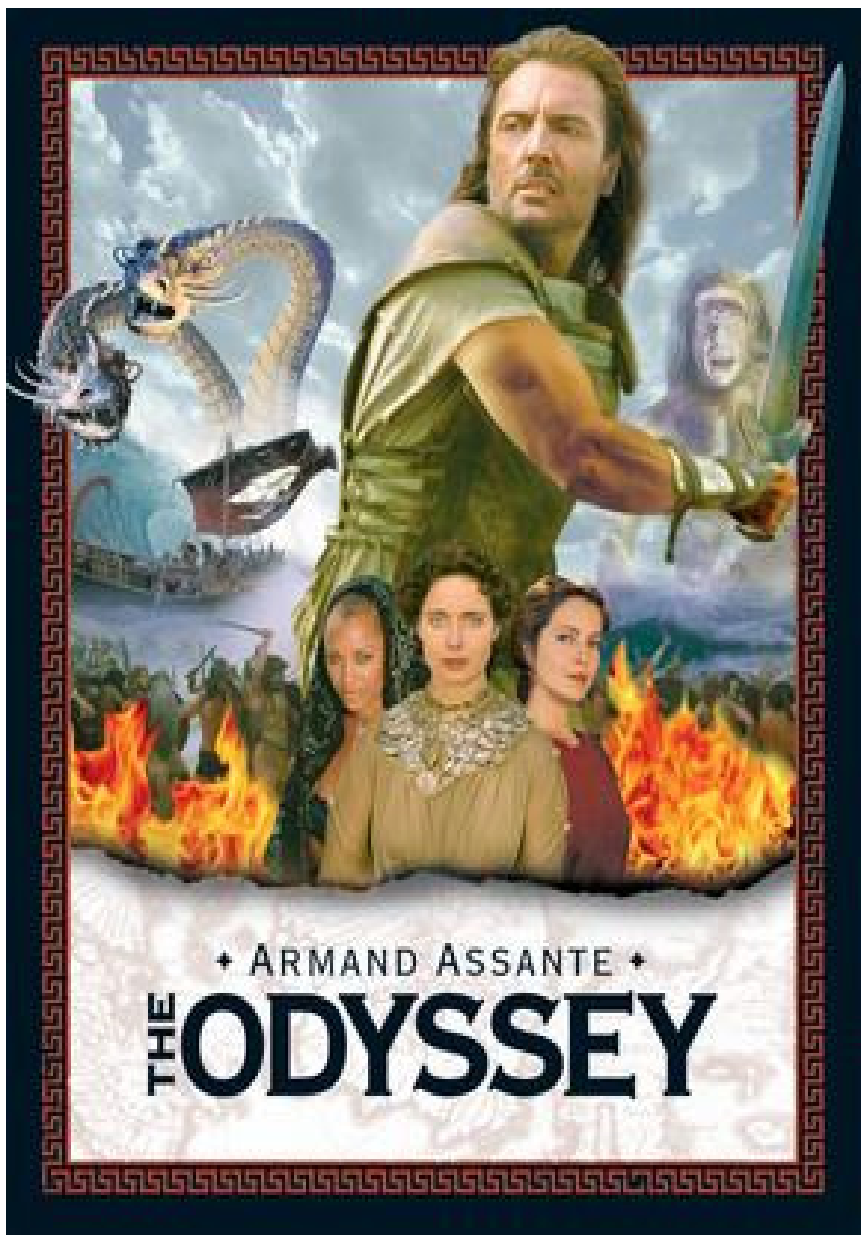


The Odyssey de A. Konchalovsky, produzida por F. F. Coppola e argumento de C. Solimine e do próprio Konchalovsky, estreou no canal norte-americano NBC, em 18 de Maio de 1997. Parte da equipa que esteve na base desta produção foi a mesma que levou ao pequeno ecrã Gulliver's Travels (1996), parcialmente filmado em Portugal, e Merlin (1998).

Em 1997, esta Odisseia foi a mais cara produção televisiva até então feita, no valor de 32 milhões de dólares. Quatro meses de rodagens, filmagens na Turquia, Malta, Grécia, além dos EUA e Reino Unido, um cavalo de madeira e vinte trirremes de tamanho natural num valor total de 250,000 dólares, um tanque maior do que um estádio de futebol, equipamentos militares gregos, efeitos especiais sofisticados, centenas de figurantes e investimento em design e concepção gráfica de criaturas por parte da The Creature Shop de J. Henson justificaram o orçamento.

Foi também este aparato que fez com que, na noite da estreia, a exibição fosse recordista de audiências nos EUA, com mais de 55 milhões de telespectadores.

Mas parte do êxito deveu-se também à agressiva e exaustiva máquina publicitária que antecedeu o mês de apresentação na América do Norte. Outras opiniões, todavia, salientam o facto de vivermos numa época de analfabetismo literário-cultural generalizado, associado a uma cultura popular excessivamente concentrada na imagem e na tecnologia, mas que, em contrapartida, acaba por ser veículo de divulgação de grandes obras de arte, conferindo uma nova vitalidade à literatura. Nesta perspectiva, a produção rica em aparato tecnológico teria contribuído para a boa recepção junto do público.

No entanto, com esta produção, confirma-se uma vez mais que grandes obras da literatura originam por norma filmes medíocres, sendo o inverso igualmente verdadeiro. A razão parece estar no facto de um filme que pretende ser fiel à qualidade do texto original tender a ficar demasiado preso às palavras, dando pouca liberdade de criação artística ao realizador. Daí que o contrário também funcione.

Em relação a esta versão da Odisseia, há inclusive quem a considere uma obra para as massas, mas também para as crianças, o que poderá não ser propriamente um elogio.

A verdade é que, ao assistirmos à proposta de Konchalovsky, deparamos com sentimentos paradoxais. É que se, por um lado, Homero é bastante cinemático, por outro é difícil recriar em imagem a genialidade dos 
seus poemas, havendo sempre uma sensação de ficar aquém do espírito das epopeias e da grandeza do Poeta.

Acresce o facto de ser impossível estabelecer comparações com outras versões cinematográficas da épica homérica, designadamente o Ulysses de M. Camerini (1954), com Kirk Douglas no papel protagonista e que é talvez a mais bem conseguida adaptação da Odisseia até hoje feita.

O principal problema da produção de Coppola parece estar no cast, totalmente miscasted, com uma ou outra honrosa excepção, e não tanto ao nível da tecnologia utilizada, da investigação realizada ou da recriação de ambientes.

Entre os actores mal escolhidos, não podemos deixar de referir Bernardette Peters, uma Circe totalmente inadequada, por ser uma actriz de teatro musical, pouco versátil no drama, que ninguém leva a sério como Circe; Isabella Rossellini, uma Atena deslocada, aparentemente saída de um anúncio de uma conhecida marca de cosméticos; Geraldine Chaplin, demasiado rígida como Euricleia; e Freddy Douglas, um Hermes excessivamente parecido com o anjo homoerótico do conhecido filme de culto de R. Vadim, Barbarella (1968).

Entre os toleráveis, consideramos Armand Assant, apesar de o seu Ulisses se descolar pouco do Napoleão que interpretou na mini-série de 1987; Greta Scacchi, com um desempenho melhor na segunda parte do que na primeira, onde é já demasiado velha para o papel que interpreta; e, claro, Vanessa Williams, uma Calipso apaixonada, mas com uma dose pasolinianofelliniana excessiva e pouco credível como ninfa-afro (bem mais como Miss América).

Ainda ao nível das interpretações, a honra é salva por Irene Papas, uma habituée do cinema de temática clássica, que como Anticleia é a mais bem inserida das intérpretes. Talvez a sua veia grega a inspire... A pose com que interpreta a cena da espera à janela, por exemplo, é, no mínimo, soberba. Uma palavra ainda para o prematuramente falecido Nicholas Clay, que teve como Menelau uma das suas últimas representações, ainda que a composição física da personagem, recordando um kouros, seja pouco credível.

Talvez esta produção seja o exemplo de que um cast «superestrelado» pode ser particularmente contraproducente.

Quanto à produção propriamente dita, o filme tem aspectos particularmente negativos. Ao contrário de Homero, que começa a narrativa à maneira clássica, i.e., in medias res, o filme opta por ajudar o espectador, contando a história pela ordem «correcta»: abre com uma cena caótica que 
desemboca no nascimento de Telémaco (inusitadamente auxiliado pelo próprio Ulisses) até à reorganização de Ítaca. Trata-se de um apoio à audiência, portanto. Mas não reside aí, e sim noutras opções, o que reconhecemos de menos bom nesta Odisseia. Vejamos os principais.

Apesar de antropomorfizados, os deuses oscilam entre a caricatura (ex: Éolo, cujo sotaque é ridiculamente americano) e a fantasia de tipo Disney e ao mesmo tempo homoerótica (ex: Hermes, mistura de «fada Sininho» com ícone «gay»). Note-se, aliás, como até o diálogo entre Hermes e Ulisses no momento da entrega da planta moly é claramente homoerótico.

Reconhecemos que a composição e reconstituição dos ambientes em geral é positiva, como mostra o caso da recriação do oikos de Ulisses ou outros aspectos da cultura material retratados nesta produção. Mas há excepções, como Esparta, por exemplo, demasiado minóica e pouco micénica ou dórica como seria suposto. Também o megaron de Ulisses é igualmente cretense, bem como as colunas que decoram a casa do herói. O ambiente de Esquéria sugere-se persa senão mesmo assírio. A rainha Arete (aqui inominada), aliás, parece ter sido directamente decalcada da estátua egípcia de Nofret. E, curiosamente, muda, em antagonismo claro com o protagonismo que de forma pertinente lhe reconhecemos na Odisseia ${ }^{1}$. O palácio de Circe tem uma bizarra forma egípcia, quando na hermenêutica de Circe nada aponta para isso (uma eventual recriação do ambiente dos Lotófagos seria o apropriado a esse cenário, mas estes estão ausentes da produção). E também, a da ilha de Calipso, enigmaticamente colocada num cenário que parece saído de um filme de Fellini ou de Pasolini, nas cascatas de Pamukkale, na Turquia (curiosamente, a localização de Ogígia é apontada mais para o Ocidente do que para o Oriente mediterrâneo).

Os grandes temas homéricos, como a hospitalidade, o festim, a dignificação do herói e a exaltação da genealogia diluem-se por completo no filme, o que, aliás, não é de estranhar, dada a complexidade em «encenar»a maioria deles. Igualmente ausente está o problema da necessidade do casamento de Penélope, tal como Homero o formula, o que se torna ainda mais problemático se levarmos em conta o facto de este ser um tema central no poema.

Outro aspecto a apontar é o facto de Aquiles aparecer sem armadura, quando esse é um dos grandes temas homéricos. A armadura é, aliás, totalmente desvalorizada nesta produção.

1 od. 7. 
Sucedem-se outras perguntas: o que aconteceu a Pátroclo? É mesmo Heitor quem desafia Aquiles? Não era suposto Aquiles arrastar o corpo de Heitor em frente às muralhas? O que aconteceu aos filhos de Laocoonte? $\mathrm{E}$ a Mentor? E a Helena? E aos doze navios de Ulisses? E à frota aqueia que foi buscá-lo? Onde estão os outros ciclopes? E onde estão as Sereias, os Lotófagos, os Lestrígones e as Vacas do Sol, todas elas criaturas de grandes potencialidades nas mãos do design Henson? E a mortalha de Laertes, outro dado estruturante da narrativa homérica? Não era suposto a moly ser uma flor branca de raiz negra? É uma erva grosseiramente arrancada! A este propósito, refira-se ainda que, quando comparado com a Eneida, o episódio de Laocoonte incluído no filme é muito pouco trágico, chegando mesmo a resvalar o ridículo. Assinale-se mesmo que se trata de um subaproveitamento do «know how Henson», que aqui desilude por completo ${ }^{2}$.

Outros pormenores, eventualmente mais irrelevantes não coincidem totalmente com o que lemos no poema (e.g. a morte de Elpenor), ou são compostos de uma forma pouco adequada ao suposto, como acontece com os marinheiros companheiros de Ulisses que, apesar de andarem no mar há pelo menos dez anos, aparecem bem barbeados e pouco crestados do $\mathrm{Sol}^{3}$.

É claro que o texto não tem de ser passado a imagem ipsis uerbis, mas alguns destes episódios, como o das Sereias (oportunidade excelente mas perdida para desmistificar a ideia de que as sereias gregas são mulheres com rabo de peixe), seriam decerto os episódios mais propensos à criatividade cinematográfica e sensíveis ao impacte do ícone.

Outras inadequações vêem-se por exemplo na excessiva importância dada a Ulisses, na arenga junto às muralhas, quando a mesma devia ter sido dada a Menelau ou a Agamémnon, e que só se justifica pelo facto de o filme ter como objectivo o protagonismo do herói da Odisseia e não nenhum outro.

Como não poderia deixar de ser, são várias as influências «cecilbedemilleanas» que se fazem sentir ao nível da cinematografia. Encontramo-las nas cenas da entrada do cavalo de Tróia, da recolha dos ventos por Éolo (que se assemelha à coluna de fogo de The Ten Commandments de 1956), e de Ulisses e Posídon, algo semelhante à da sarça ardente protagonizada por Moisés e Javé no Monte Horeb, também no filme de 1956.

2 Vide a propósito o filme Jim Henson's The Storyteller - Greek Myths (1997).

3 Pormenor já notado por C. Paglia, «Homer on Film: a Voyage through "The Odyssey, Ulysses, Helen of Troy", and "Contempt”», Arion 5, 1997, 166-197. 
Assim, em síntese, consideramos que os episódios particularmente falhados desta produção são o de Éolo, apesar dos efeitos especiais utilizados; o de Circe, em que a escolha da actriz para interpretar a feiticeira foi um desaire total; e o de Nausícaa e Esquéria, em que, acima de tudo, as figuras femininas são totalmente anuladas, eliminando grande parte do interesse do episódio. Mas há também que destacar o positivo e entre os episódios conseguidos, consideramos o do Ciclope, cuja encenação e cinematografia sugere os conhecidos frescos odisseicos do Esquilino; o da Catábase, apesar da androginia de Tirésias, do fogo excessivamente dantesco e do ambiente egípcio dado ao lugar; o de Cila e Caríbdis, apesar das inegáveis reminiscências do filme de R. Scott, Alien (1979), e respectivas sequelas; e o de Calipso, apesar de o ambiente utópico-paradisíaco descrito por Homero se diluir e desaparecer para dar lugar às cascatas calcárias da Turquia.

The Odyssey de Konchalovsky acabou por ganhar um prémio na categoria de «Outstanding Directing for a Miniseries or a Special». 


\begin{tabular}{|c|c|}
\hline Ficha Técnica & Ficha Artística \\
\hline $\begin{array}{l}\text { Produção - Francis Ford Coppola, } \\
\text { Dyson Lovell } \\
\text { Duração - } 176 \text { m. } \\
\text { Realização - Andrei Konchalovsky } \\
\text { Argumento - Andrei Konchalovsky, } \\
\text { Christopher Solimine } \\
\text { Fotografia (cores) - Sergei Kozlov } \\
\text { Música - Eduard Artemiev } \\
\text { Cenografia - Karen Brookes } \\
\text { Guarda-Roupa - Charles Knode } \\
\text { Montagem - Michael Ellis } \\
\text { Observações: vencedor de um } \\
\text { prémio na categoria de «Outstanding } \\
\text { Directing for a Miniseries or a } \\
\text { Special». }\end{array}$ & $\begin{array}{l}\text { Armand Assante - Ulisses } \\
\text { Greta Scacchi - Penélope } \\
\text { Isabella Rossellini - Atena } \\
\text { Bernadette Peters - Circe } \\
\text { Eric Roberts - Eurímaco } \\
\text { Irene Papas - Anticleia } \\
\text { Jeroen Krabbé - Alcínoo } \\
\text { Christopher Lee - Tirésias } \\
\text { Vanessa Williams - Calipso } \\
\text { Nicholas Clay - Menelau } \\
\text { Paloma Baeza - Melanto } \\
\text { Rob Cook - Euríbates } \\
\text { Katie Carr - Nausícaa } \\
\text { Alan Cox - Elpenor } \\
\text { Alan Stenson - Telémaco } \\
\text { Heathcote Williams - Laocoonte } \\
\text { Tony Vogel - Eumeu } \\
\text { Richard Truett - Aquiles } \\
\text { Yorgo Voyagis - Agamémnon } \\
\text { Derek Lea - Heitor } \\
\text { Freddy Douglas - Hermes }\end{array}$ \\
\hline
\end{tabular}

Bosque d'Ouro, 17 de Maio de 2011

NUNO SIMÕES RODRIGUES 